\title{
A Utilização de Vídeos no Ensino: Uma Experiência Prática com Alunos de Graduação
}

\author{
Vinícius Cooper-Capetini', Amanda Gomes Pereira², Bruna Bezerra Lins', José Sinésio Silva- \\ Junior ${ }^{1}$, Leonardo Vinícius Monteiro de Assis ${ }^{3}$, Luciana Tocci Belpiede ${ }^{1}$, Marcos Rodrigo Jerônimo \\ da Costa $^{3}$, Patrícia Pereira Nunes ${ }^{1}$, Regiane Cardoso Castelo-Branco ${ }^{1}$ e Maria Tereza Nunes ${ }^{1}$ \\ ${ }^{1}$ Departamento de Fisiologia e Biofísica, Instituto de Ciências Biomédicas da Universidade de São Paulo \\ ${ }^{2}$ Departamento de Ciências Básicas, Universidade Estadual Paulista \\ ${ }^{3}$ Departamento de Fisiologia, Instituto de Biociências da Universidade de São Paulo \\ * Autor para correspondência: viniciuscooper@usp.br
}

\section{RESUMO}

O ensino de fisiologia endócrina faz parte do currículo dos estudantes da área de Ciências Biomédicas. Contudo, em função da necessidade de um conjunto de conhecimentos bem fundamentados de Biologia Celular, Molecular e Bioquímica, há dificuldade na assimilação desse tópico, principalmente por alunos dos primeiros dois anos de graduação, o que cria a necessidade do uso de diferentes estratégias de ensino-aprendizagem para a apropriação desses conhecimentos. Quando empregado de forma coerente com a proposta pedagógica, o vídeo em sala de aula pode ser uma ferramenta útil para a superação dessa dificuldade. Com esse intuito nos propusemos a utilizar essa estratégia junto aos alunos do primeiro semestre de graduação da Escola de Educação Física e Esporte da Universidade de São Paulo, como uma atividade em grupo em sala de aula, a fim de motivá-los a desenvolver uma leitura crítica da mídia em relação ao conteúdo de Fisiologia Endócrina, mais especificamente de fisiologia das glândulas adrenais e do metabolismo do cálcio e do fósforo. Com a introdução dos vídeos em sala de aula, tornaram-se notórios o maior interesse e o envolvimento dos alunos na realização das atividades propostas, possibilitando: (a) melhor aproveitamento do conteúdo previamente trabalhado em sala de aula, o que certamente facilitou o aprendizado; e (b) o estabelecimento de correlações entre fatos do cotidiano e a liberação e ação de hormônios naquele contexto determinado.

Palavras-chave: Vídeo; Ensino de Fisiologia Endócrina; Educação; Graduação; Contextualização.

\begin{abstract}
The endocrine physiology teaching is part of the curriculum of the students of the Biomedical Sciences area. However, the need of a set of well-founded knowledge of Cell and Molecular Biology, as well as Biochemistry subjects, turns this topic very difficult to be understandable, mainly for the students of the first semesters. This creates the need of using different teaching and learning strategies for the appropriation of these knowledges. When applied in a coherent way in conjunction with the pedagogical proposal, the use of videos in the classrooms could be a useful tool to help to overcome this difficulty. In this context, we have used this strategy as a group activity in the classroom, with undergraduate students of the first semester of the Faculty of Physical Education and Sport of the Universidade de São Paulo. We aimed to lead them to develop a critical evaluation of the media in relation to Endocrine Physiology content, specifically the physiology of the adrenal glands and the calcium and phosphorus metabolism. With the introduction of videos in the classroom, it became notorious the great interest and involvement of the students in carrying out the proposed activities. This allowed: (a) a better comprehension of the content previously taught in the classroom, which certainly facilitated the learning process and (b) the ability to make correlations between routine events and the release of hormones and their action in that specific context.
\end{abstract}

Keywords: Video; Endocrine Physiology Teaching; Education; Undergraduation; Contextualization.

\section{Introdução}

A evolução das tecnologias digitais cria um ambiente favorável para a modificação dos métodos tradicionais de ensino, possibilitando o surgimento de novas estratégias (KENSKI, 2003). São muitos os métodos de ensino-aprendizagem utilizados 
no ensino dos cursos de graduação (ALENCAR, 2002; LELLIS-SANTOS, GIANNOCCO \& NUNES, 2011), e o avanço tecnológico estimula as instituições a desenvolverem novas alternativas aos métodos tradicionais de ensino e permite maior participação dos alunos no processo de aprendizagem, motivando o desenvolvimento de um pensamento crítico e reflexivo, crucial para a formação de qualquer profissional (SOUSA, MOITA \& CARVALHO, 2011).

A formação dos profissionais da área de Ciências Biomédicas requer, para a maioria dos cursos, a disciplina de Fisiologia, sendo notória sua importância na formação de médicos e outros profissionais dessa área. Entretanto, ao cursarem essa disciplina os alunos geralmente apresentam dificuldades em assimilar o conteúdo proposto, especialmente o conteúdo de Fisiologia Endócrina, que requer o conhecimento prévio de Bioquímica, Biologia Celular e Molecular, Fisiologia Geral e de Sistemas, além da capacidade do aluno de encadear esses conhecimentos entre si. Várias estratégias de ensino têm sido utilizadas para superar essas dificuldades, incluindo: o aprendizado baseado em problemas; mapas conceituais; atividades no laboratório de informática; aulas práticas; pesquisas bibliográficas; vídeos e outras atividades que permitam aos alunos um envolvimento mais ativo e significativo no processo de aprendizagem (LELLIS-SANTOS, GIANNOCGO \& NUNES, 2011).

Entre as estratégias utilizadas para tornar as aulas mais atrativas e eficientes, o uso de vídeos em um processo de aprendizagem não é novidade. Desde que vídeos foram usados no treinamento de soldados durante a Segunda Guerra Mundial (HOVLAND, LUMSDAINE \& SHEFFIELD, 1949), os educadores têm dado maior importância à capacidade dos recursos audiovisuais para despertar a atenção dos alunos, aumentando a motivação e melhorando o processo de aprendizagem. Entretanto, desde o período da guerra, o conteúdo e a tecnologia dos recursos audiovisuais desenvolveram-se consideravelmente, com o surgimento de mídias sociais e a maior disponibilidade e a qualidade desses recursos em sala de aula (CORPORATION FOR PUBLIC BROADCASTING, 2004). Atualmente as mídias sociais, como os sites de vídeos, auxiliam na promoção de um processo de ensino-aprendizagem servindo como ferramentas eficazes que se somam às técnicas mais tradicionais do processo de ensino (BUZZETTO-MORE, 2012).

Nos Estados Unidos, segundo os estudos realizados pela Corporation for Public Broadcasting (2004), o uso de vídeos educativos e da televisão nas salas de aula tem aumentado de forma crescente ao longo dos últimos anos. Esses recursos audiovisuais, além de possibilitarem a facilitação do processo de ensino-aprendizagem, também são valorizados por agregarem uma forma mais eficaz e criativa de ensino, que inclusive pode ter um alcance como atividade extramuros. Esses estudos mostraram ainda que, entre os professores que relataram usar filmes e vídeos, dois terços reportam que os alunos apresentam maior índice de aprendizado. Segundo a maioria dos professores entrevistados, o uso de vídeos permitiu: maior motivação e entusiasmo dos estudantes; melhor aprendizagem; deu reforço ao material de leitura disponível e melhorou a compreensão e discussão dos temas pelos alunos.

No Brasil, Morán (1995) foi um dos primeiros pesquisadores a escrever sobre o uso de vídeos em sala de aula, apresentando as diversas linguagens dos vídeos e o impacto do uso desse recurso audiovisual em uma comunicação eficaz entre professores e alunos. Esse autor demonstrou que os vídeos podem ser utilizados em sala de aula como um instrumento de leitura crítica da mídia e que a incorporação dessa tecnologia ao ensino auxilia na formação de alunos mais conscientes. Segundo Arroio e Giordan (2006), ao assistir ao vídeo, além da transmissão de conteúdos, é proporcionado ao telespectador vivenciar as sensações, emoções, atitudes, ações e conhecimentos, facilitando o processo de ensino-aprendizagem. Adicionalmente, os recursos audiovisuais mobilizam, de modo mais efetivo, a visão e a audição. Para a geração contemporânea, que nasceu e cresceu em um mundo 
globalizado, é nevrálgico o impacto das mídias audiovisuais, e elas se tornam cada vez mais presentes conforme as tecnologias avançam.

Davel, Vergara e Ghadiri (2007) citam diversas experiências de sucesso com a utilização de vídeos no processo de ensino-aprendizagem. As dificuldades de concentração dos alunos nas disciplinas de Teorias da Administração I e II do curso de Administração foram superadas com a introdução de filmes, possibilitando uma excelente relação pedagógica e pessoal com os alunos. No curso de pós-graduação em Administração Pública, relataram que a introdução de vídeos em sala de aula gerou discussões e debates relevantes e a turma mostrou-se mais motivada a participar das aulas. Por outro lado, Morán (1995) alerta que o uso inadequado do vídeo pode ser desastroso para o processo de ensino-aprendizagem, exigindo do professor um senso crítico apurado, pensando não apenas nas qualidades audiovisuais, mas se o vídeo selecionado é relevante para esse processo ou se é apenas um entretenimento. Vídeos bem selecionados, mesmo que de mídias sociais como YouTube, podem ajudar os alunos a se envolverem mais profundamente com o assunto e a recordarem a informação que aprenderam (BURKE \& SNYDER, 2008; HILNER, 2012).

Com o intuito de tornar os métodos tradicionais de ensino de fisiologia mais atrativos e eficientes, despertando o interesse dos alunos para esse conteúdo, o presente artigo propõe a utilização de vídeos em sala de aula como uma estratégia do ensino de Fisiologia Endócrina. As aulas de fisiologia da glândula adrenal e do metabolismo do cálcio e do fósforo foram suplementadas com vídeos que objetivaram estimular o pensamento crítico e uma atitude mais ativa dos alunos de graduação da Escola de Educação Física e Esporte (EEFE) da Universidade de São Paulo. Foi proposta uma atividade em grupo com o uso de dois vídeos em sala de aula a fim de motivar os alunos a desenvolverem uma leitura crítica da mídia em relação ao conteúdo pedagógico trabalhado.

É importante ressaltar que essa intensa exposição e o contato com os meios audiovisuais no cotidiano criaram uma produção e difusão de informações quase absolutas, que, em larga medida, não passam por filtros críticos ou reflexivos. Dessa forma, fazem-se fundamentais a discussão desses conteúdos e o desenvolvimento das capacidades críticas dos estudantes, para que estes se tornem sujeitos e não espectadores no processo de ensino. O uso não adequado de ferramentas audiovisuais pode vir a ser "mais do mesmo", uma vez que o acesso a essas tecnologias é quase natural para os alunos e a população em geral.

\section{Desenvolvimento}

Atendendo ao plano pedagógico da disciplina de Estruturação de um Programa de Ensino de Fisiologia Endócrina Dirigido à Capacitação Docente (BMB5787), ministrada pela professora Maria Tereza Nunes do Instituto de Ciências Biomédicas da Universidade de São Paulo, os alunos da pós-graduação matriculados nessa disciplina tiveram que planejar estratégias de ensino que complementassem as aulas teóricas ministradas pela mesma professora na disciplina de Fisiologia (BMB108) no curso de graduação em Educação Física e Esporte. Para isso, foram apresentados durante as aulas de fisiologia das glândulas adrenais e do metabolismo do cálcio e do fósforo alguns vídeos contemporâneos, de ficção e realidade, com o intuito de estimular os alunos a realizarem uma leitura crítica dos casos apresentados pela mídia em relação ao conteúdo teórico discutido nas aulas.

$\mathrm{Na}$ aula de fisiologia das glândulas adrenais foram transmitidos um trecho do filme Babel (2006) e uma reportagem sobre o caso do "Monstro de Amstetten" (PAI MONSTRO DA ÁUSTRIA, 2008), ambos os vídeos com aproximadamente oito minutos de duração.

No trecho selecionado do filme Babel, dois adolescentes marroquinos decidem testar o alcance do rifle dado pelo pai, mirando primeiro em pedras e depois em um ônibus que transportava turistas em um deserto no Marrocos. O tiro de um dos adolescentes atinge o ônibus, ferindo gravemente a personagem Susan Jones (Cate Blanchett), que viajava em férias com seu marido Richard Jones 
(Brad Pitt). Devido ao ferimento, Susan apresenta hemorragia, e o ônibus então parte para a vila mais próxima à procura de cuidados médicos, mas ela recebe apenas um tratamento rudimentar; enquanto sofre com os sintomas típicos do ferimento à bala e mesmo com hemorragia, a personagem sente necessidade de urinar (BABEL, 2006).

$\mathrm{O}$ outro vídeo apresentado versava sobre o caso do "Monstro de Amstetten", que impressionou o mundo por tamanha crueldade. O pai, Josef Fritzl, aprisionou, no porão de sua casa, a filha Elizabeth Fritzl durante 24 anos e com ela praticou incesto e teve sete filhos, um dos quais morreu logo após nascer, tendo Josef incinerado o seu corpo ao jogá-lo no sistema de calefação da casa. Três de seus filhos nunca haviam visto a luz do sol, e a filha mais velha, de dezenove anos, ao ser internada em estado crítico, apresentava deficiência de vitamina D. A dieta das vítimas era baseada em batatas, macarrão, enlatados e água, raramente frutas, verduras e carnes. Na definição dos policiais que resgataram as vítimas do cativeiro em abril de 2008, Elizabeth tinha a cor da pele branco-acinzentada como a de um cadáver e os filhos estavam sem músculos no corpo. No dia 19 de março de 2009, Fritzl foi julgado culpado e condenado à prisão perpétua pelos crimes de cárcere privado, estupro, incesto e homicídio (PAI MONSTRO DA ÁUSTRIA, 2008).

Após assistir aos vídeos, os alunos foram divididos em grupos para discutirem, à luz deles, a participação dos hormônios das glândulas adrenais nas situações apresentadas, apontando suas possíveis ações e repercussões sistêmicas, a partir das seguintes questões:

a. Considerando a glândula endócrina estudada hoje e conforme observado no trecho do filme Babel, discorra sobre a ação de seus hormônios na hemorragia, explicando quais são e como estariam agindo nesse caso.

b. Na reportagem sobre o caso do "Monstro de Amstetten", é possível observar que os encarcerados sofreram por vários anos estresse por enclausuramento. Nesse caso, qual seria o principal hormônio responsável por essa situação? Como estaria sua secreção? E quais as consequências metabólicas desse estado para a saúde?

Os alunos conseguiram aplicar, na discussão em grupo, o conhecimento adquirido durante as aulas teóricas, de forma a responderem as questões sugeridas a partir das cenas, havendo encontrado, por exemplo, possíveis falhas na filmagem de $B a$ bel, cuja personagem relata vontade de urinar mesmo estando com hemorragia. Segundo Koeppen e Stanton (2010), imediatamente após a perda sanguínea aguda há variações da pressão arterial, que indicam que certos mecanismos compensatórios devem estar operando, como a liberação de catecolaminas e aldosterona pelas glândulas adrenais, entre outros mecanismos. A secreção das catecolaminas epinefrina e norepinefrina pela medula suprarrenal é regulada, principalmente, pela sinalização simpática descendente, em resposta à hipovolemia hemorrágica, reforçando os efeitos da atividade nervosa simpática como a redução do tônus vagal, aumento da frequência cardíaca, da contratilidade do miocárdio e da vasoconstrição. Em paralelo a esse efeito, a hemorragia também desencadeia o aumento na secreção da aldosterona, que estimula a reabsorção de $\mathrm{NaCl}$ pelos néfrons, aumentando a retenção de $\mathrm{NaCl}$ e água, diminuindo dessa forma a perda hídrica através da urina e consequentemente a micção. Adicionalmente, nessa situação o hormônio antidiurético tem também sua secreção aumentada, o que aumenta a reabsorção renal de água, reduzindo sua excreção pela urina.

Ao assistirem à reportagem sobre o caso do "Monstro de Amstetten", os alunos também conseguiram identificar que o enclausuramento pode ter ocasionado, especialmente para Elizabeth, que por várias vezes foi obrigada a manter relação sexual com o próprio pai, momentos de medo e estresse em que a secreção do cortisol pelo córtex adrenal possivelmente estava alta, e em longo prazo pode ter causado diversos distúrbios metabólicos. Em resumo, conforme também descrito pelos alunos, o excesso de cortisol apresenta, entre várias altera- 
ções metabólicas: uma atividade imunossupressora, diminuindo o número de linfócitos $\mathrm{T}$ e causando a atrofia do timo; resistência à insulina; hiperlipidemia; perda da massa óssea (osteoporose); inibição da proliferação fibroblástica e da formação de colágeno tornando a pele mais fina e mais susceptível a lesões; proteólise excessiva no tecido muscular gerando fraqueza e dor muscular; surgimento de úlceras pépticas; instabilidade emocional, depressão e insônia (KOEPPEN \& STANTON, 2010).

Na aula sobre regulação hormonal do metabolismo do cálcio e do fósforo, o vídeo sobre o caso do "Monstro de Amstetten" foi reapresentado, porém com um novo enfoque, e os alunos, após assistirem a ele novamente, tiveram de discutir em grupo e responder as seguintes questões:

a. A reportagem retrata indivíduos que passaram anos trancados e sem qualquer exposição ao ambiente externo. O que você espera ter ocorrido com esses indivíduos, levando em consideração o que foi abordado e discutido na aula de hoje?

b. Quais hormônios estariam atuando nessa situação? Quais os mecanismos envolvidos na sua síntese e liberação?

c. Quais as repercussões para o nosso organismo?

Ao assistirem novamente à reportagem sobre o caso do "Monstro de Amstetten", os alunos também conseguiram identificar que o enclausuramento, além de causar os problemas relacionados ao estresse e ao medo constantes, foi responsável pela ausência de exposição solar que, aliada ao consumo de uma dieta composta basicamente de batatas, macarrão, enlatados e água, ocasionou a deficiência de vitamina D. Em humanos, apenas $10 \%$ a $20 \%$ da vitamina $\mathrm{D}$ necessária às funções do organismo provém da dieta. As principais fontes dietéticas de vitamina $\mathrm{D}$ são os peixes gordurosos de água fria e profunda, como o atum e o salmão, e, em menor quantidade, a sardinha, o fígado e o leite. Os $80 \%$ a 90\% restantes são sintetizados endogenamente (HOLICK, 2008), quando, por meio da exposição solar, o 7-dehidrocolesterol, produzido na derme e epiderme, isomeriza-se em colecalciferol e no fígado sofre a ação da enzima 25-hidroxilase, transformando-se em 25-hidroxivitamina D. No rim, essa molécula é convertida na forma ativa 1,25-di-hidroxivitamina $\mathrm{D}$ pela ação da enzima 1, alfa-hidroxilase, que é ativada pelo paratohormônio (PTH) ou por redução da calcemia, e, na forma inativa, 24,25-hidroxivitamina D pela ação da enzima 24,25-hidroxilase. A ação clássica da 1,25-di-hidroxivitamina $\mathrm{D}$ é promover a absorção do cálcio e, em menor grau, do fósforo pelo intestino delgado, e a reabsorção de $\mathrm{Ca}^{++}$pelos rins e ossos, sendo que nestes também participa do processo de mineralização (FRASER, 1995).

Os alunos igualmente foram capazes de descrever que, com a falta da exposição solar e uma ingestão alimentar insuficiente de vitamina $\mathrm{D}$, as vítimas do "Monstro de Amstetten" provavelmente apresentavam uma baixa concentração plasmática de vitamina $\mathrm{D}$ e consequentemente uma absorção insuficiente de cálcio e hipocalcemia, ocasionando um aumento na secreção de PTH pelas paratireoides. O PTH estimula a expressão da 1- $\alpha$-hidroxilase, convertendo a 25-hidroxivitamina D em 1,25-di-hidroxivitamina D, ao mesmo tempo que aumenta a absorção de cálcio e a excreção de fosfato pelos rins. Nos ossos, esse hormônio aumenta a atividade osteoclástica, promovendo maior reabsorção óssea e, consequentemente, liberação de cálcio e fósforo para o sangue (FRASER, 1995). Além disso, a 1,25-di-hidroxivitamina D também atua na mineralização óssea, e sua deficiência em crianças pode resultar em raquitismo, doença óssea caracterizada pela diminuição da sua mineralização, e em adultos pode causar a osteomalácia, com acúmulo de tecido osteoide não mineralizado ou pouco mineralizado (RYAN et al., 2013).

A partir dos casos apresentados, tanto no trecho do filme Babel como na reportagem do caso do Monstro de Amstetten, os alunos conseguiram identificar os mecanismos fisiológicos de interesse decorrentes das situações em que as vítimas foram expostas, e responder as questões referentes aos episódios. A aplicação dessa estratégia de ensino-aprendizagem auxiliou na fixação dos conteúdos de fisiologia da glândula adrenal e do metabolismo do cálcio e do fósforo. Portanto, os vídeos usados 
foram importantes aliados para tornar mais eficazes os métodos tradicionais de ensino-aprendizagem, pois os alunos assistem aos filmes como entretenimento, e não como uma aula habitual. Isso altera a relação entre aluno e professor, gerando novas perspectivas pedagógicas, afinal desperta, naturalmente, a atenção dos graduandos para o assunto que se quer abordar (MORÁN, 1995). Também possibilita ao aluno ser mais crítico, reflexivo e protagonista de seu próprio aprendizado, e coloca o professor como um facilitador desse processo (ALENCAR, 2002).

Associada ao uso dos vídeos, a opção pela formação de grupos para a discussão das questões gerou mais interação entre os estudantes, permitindo que eles compartilhassem os seus conhecimentos. Segundo Teixeira (1999), a discussão coletiva contribui para o desenvolvimento de valores como o respeito pelo outro, sociabilidade e cooperação, elementos primordiais para o processo de aprendizagem e para o fazer científico.

A análise dos conteúdos apresentados pelos alunos no final da atividade revelou que eles foram capazes de relacionar, pontualmente e com êxito, os fatos expostos nos vídeos com os conteúdos teóricos de fisiologia endócrina discutidos previamente, bem como souberam apontar certas inconsistências veiculadas no trecho do filme, que careciam de uma base fisiológica. Essa estratégia de ensino-aprendizagem facilitou a fixação dos conceitos necessários para a compreensão da disciplina e a formação de um pensamento crítico, tornando-os capazes de entender e aplicar seus conhecimentos dentro da realidade que os cerca.

\section{Conclusão}

A introdução dos vídeos nas aulas de fisiologia das glândulas adrenais e do metabolismo do cálcio e do fósforo, associada ao trabalho em grupo, permitiu a discussão e a aplicação prática dos assuntos abordados, sendo notório o maior interesse e o envolvimento dos alunos na realização das atividades propostas, possibilitando: (a) melhor aproveitamento do conteúdo previamente trabalhado em sala de aula, o que certamente facilitou o aprendizado; (b) a capacidade de fazer uma leitura crítica da mídia em relação ao assunto estudado; e (c) a construção propriamente dita do conhecimento de fisiologia endócrina e a sua contextualização.

\section{Referências Bibliográficas}

ALENCAR, E. M. L. S. "O Contexto Educacional e sua Influência na Criatividade". Linhas Críticas, vol. 8, n. 15, pp. 165-178, 2002.

ARROIO, A. \& GIORDAN, M. "O Vídeo Educativo: Aspectos da Organização do Ensino". Química Nova na Escola, n. 24, pp. 7-10, 2006.

BABEL. Direção: Alejandro González Iñárritu. Produção: Alejandro González Iñárritu, Jon Kilik, Steve Golin. Música: Gustavo Santaolalla. Cinematografia: Rodrigo Prieto. Estúdio: Paramount, 2006.

BURKE, S. \& SNYDER, S. "YouTube: An Innovative Learning Resource for College Health Education Courses". International Electronic Fournal of Health Education, vol. 11, pp. 39-46, 2008.

BUZZETTO-MORE, N. "Social Networking in Undergraduate Education". Interdisciplinary Fournal of Information, Knowledge, and Management, vol. 7, pp. 63-90, 2012.

CORPORATION FOR PUBLIC BROADCASTING (2004). Television Goes to School: The Impact of Video on Student Learning in Formal Education. Disponível em: <http://www.cpb.org/stations/reports/tvgoesto school/>. Acessado em 8 mar. 2016.

DAVEL, E.; VERGARA, S. C. \& GHADIRI, D. P. (orgs.). Administração com Arte: Experiências Vividas de Ensino-Aprendizagem. São Paulo: Atlas, 2007.

FRASER, D. R. "Vitamin D". Lancet, vol. 345, pp. 104-107, 1995.

HILNER, J. "How to Use On-line Video in Your Classroom: How Teachers Can Bring the Best of YouTube and Other On-line Video Services to Their Students". Edutopia, 31 ago. 2012. Disponível em: <http:// www.edutopia.org/youtube-educational-videos-classroom >. Acessado em 5 mar. 2016.

HOLICK, M. F. "Vitamin D: a D-Lightful Health Perspective". Nutrition Reviews, vol. 66, n. 10, pp. 182194, 2008.

HOVLAND, C. I.; LUMSDAINE, A. A. \& SHEFFIELD, F. D. "Experiments on Mass Communication". Social Forces, vol. 28, n. 4, pp. 446-447, 1949.

KENSKI, V. M. Tecnologias e Ensino Presencial e a Distância. Campinas, São Paulo: Papirus, 2003.

KOEPPEN, B. M. \& STANTON, B. A. Berne む Levy Physiology. 7th ed. Philadelphia: Mosby Elsevier, 2010.

LELLIS-SANTOS, G.; GIANNOCCO, G. \& NUNES, M. T. "The Case of Thyroid Hormones: 
How to Learn Physiology by Solving a Detective Case". Advances in Physiology Education, vol. 35, n. 2, pp. 219-226, 2011.

MORÁN, J. M. "O Vídeo na Sala de Aula". Comunicação \& Educasãa o, vol. 2, pp. 27-35, 1995.

PAI MONSTRO DA ÁUSTRIA. Category: News \& Politics. License: Standard YouTube License, 4 maio 2008. Disponível em: $<$ https://www.youtube.com/watch? $\mathrm{v}=\mathrm{KdMGByYqJAc}>$. Acessado em 15 mar. 2014.

RYAN, J. W.; ANDERSON, P. H.; TURNER, A.
G. \& MORRIS, H. A. "Vitamin D Activities and Metabolic Bone Disease". Clinica Chimica Acta, vol. 21, n. 425, pp. 148-152, 2013.

SOUSA, R. P.; MOITA, M. C. S. C. \& GARVALHO A. B. G. (orgs.). Tecnologias Digitais na Educaşão. Campina Grande: EDUEPB, 2011.

TEIXEIRA, C. F. Compreensão, Criacãa e Resolução de Problemas de Estrutura Multiplicativa: uma Sequência Didática com Problemas "Abertos" (Monografia). Recife: UFPE/Curso de Especialização em Ensino de Pré a 4 a série, 1999.

Publicado em 30/06/2017. 